\title{
PERFORMANCE ANALYSIS OF GEOGRAPHICAL ROUTING PROTOCOL IN MOBILE AD HOC NETWORK
}

\author{
Omar Faruque ${ }^{1}$, Tadiwa Elisha Nyamasvisva ${ }^{2}$, Abdullahi Mujaheed Saleh ${ }^{3}$, Hasliza Binti Hashim ${ }^{4}$ \\ ${ }^{1,2,3,4}$ Faculty of Engineering Science and Technology (FEST), Department of Networking, Infrastructure University Kuala Lumpur \\ (IUKL), Bangi, Malaysia \\ Email: ${ }^{1}$ omarfaruque2050@gmail.com, ${ }^{2}$ tadiwa.elisha@iukl.edu.my, ${ }^{3}$ mujaheed05@gmail.com, ${ }^{4}$ hasliza@iukl.edu.my
}

\begin{abstract}
Wireless technology has brought a very advanced change in the field of the internet. It has given rise to many new applications. In recent years, a lot of work has been done in the field of Mobile Ad hoc Networks (MANET) which makes it so popular in the area of research work. MANET is an infrastructure-less, dynamic network that consists of a collection of wireless mobile nodes, and the communication between these nodes has been carried out without any centralized authority. There are several network performance metrics, Packet Loss and End-to-End Delay which can be taken into account, for getting a general idea about the performance of the Geographical Routing Protocol in Mobile Ad-Hoc Networks. The proposed research will evaluate the parameters which affect the communication in the Geographical Routing Protocol in Mobile Ad-Hoc Networks.
\end{abstract}

Keywords: GRP, MANETS, end to end delay, Packet Loss

\section{Introduction}

Due to technological advancement, especially after the world-wide-web and wireless internet, a lot of the latest internet technologies have come onto the horizon. During the past few decades, the evolution of these wireless technologies has enabled development in the field of wireless technologies for achieving satisfaction for end-users. A mobile ad hoc network (MANET) also known as a wireless ad hoc network is a continuously self-configuring, infrastructure-less network of mobile devices connected wirelessly. It is a network that is the collection of mobile nodes without using any central access point or an accessible framework. It is considered as an alternative to existing infrastructure-based wireless networks. In this work, we consider the Geographic Routing Protocol (GRP) as OPNET's custom MANET routing protocol whose routing is based on the shortest geographical distance between source and destination. Each node uses the GPS to identify its position and flooding will be optimized by quadrants. It is a proactive routing protocol where routes are available only when they are needed. Position-based routing or geographic routing is used to eliminate the limitations of topology-based routing. It gives better performance in dynamic topologies because the packets are forwarded to their destination concerning their position.

To design and analyze the wireless networks there is a great need of implementing Geographic Routing Protocol (GRP) in MANET. There are some problems with security, bandwidth, power limitation, Network delay of mobile devices, etc. This work will try to analyze Energy Efficient Forwarding Strategies for Geographic Routing (EEFS) related problems in GRP activated MANETs.

\section{A. Problem Statement}

To analyze the GRP wireless networks there is a need of implementing Geographical Routing Protocol in Mobile Ad-Hoc Networks. Many networks are moving from wired to a wireless network because of user demands such as open office and BYOD. Users are also able to share files and other resources with other devices that are connected to the network without having to be cabled to a port. Users generally love wireless networks because they are convenient.

Traditional mobility management approaches are based on client/server paradigms and suffer from their wellknown shortcomings. With the success of Peer-to-Peer (P2P) for file sharing applications, its benefits can be brought into new mobility management schemes to improve their scalability, availability, and performance. Locality-awareness is one of the essential characteristics for P2P systems, especially for Mobile Ad-hoc Networks (MANETs), which build and operate their topology independently of the underlying physical network topology [1]. Which routing protocol and set up produce the best results in mobile networks.

\section{B. Objectives}

This research focuses on the proposed study of exploring the factors related to the Geographical Routing Protocol in Mobile Ad-Hoc Networks with the following objectives

i. To evaluate GRP, FTP, and HTTP Protocols in terms of delay in different topologies.

ii. To compare Network performances of different topologies for MANETs.

\section{Review Of Literature}




\section{A. Geographic Routing Protocols}

There are several PRPs available such as, Greedy Perimeter Stateless Routing (GPSR): GPSR is one of the most popularly used Geographic routing protocols in ad hoc networks. GPSR uses the location of the node in the network to selectively forward the packets based on the distance. Two algorithms are used in GPSR: Greedy forwarding and Face routing. Whenever greedy forwarding fails, the algorithm uses a face routing strategy to route around the communication voids and reaches the destination. Once the other node comes in the transmission range, the algorithm switches back to the Greedy forwarding reducing the delay and increasing the performance.[2] [3]

Most Forward within Radius (MFR): It is a progressbased algorithm, in which data is forwarded to the neighbor with the greatest progress. Its objective is to maximize obtainable expectable progress in a certain direction. If no node is in the forward direction, within the range of the sender, the message is sent to the neighbor node with the least backward progress. This algorithm minimizes the number of hops, energy consumption.[4]

Greedy Other Adaptive Face Routing (GOAFR): This algorithm starts with greedy forwarding and switches to face routing when reaching a local minimum concerning the distance of the current node from the destination. The face routing technique that GOAFR employs has two major differences compared to the traditional face routing. GOAFR also explores the boundaries of a face by employing the righthand rule [2][5].

Energy Efficient Forwarding Strategies for Geographic Routing (EEFS): This geographic protocol assumes a positioning system to account for the location knowledge. It assumes nodes are randomly distributed in the network and aims to improve energy efficiency considering distance and reception rate in the routing decisions. The study is performed with and without ARQ, considering aggregation possibilities. A compromise between the shortest path has to be made by considering the transitional region between the two possible strategies. [6][7].

\section{B. Mobile Ad Hoc Networking (MANET)}

Mobile Ad Hoc Networks (MANETs) are an emerging type of wireless networking, in which mobile nodes associate on an extemporaneous or ad hoc basis. MANETs are both self-forming and self-healing, enabling peer-level communications between mobile nodes without reliance on centralized resources or fixed infrastructure. The network topologies are dynamic and may vary from time to time. Each device must act as a router for transferring any traffic among each other. This network can operate by itself or incorporate into a large area network (LAN).[8][9].

\section{a. Advantages of MANET}

i. They provide access to information and services regardless of geographic position

ii. Independence from central network administration. Self-configuring network, nodes also act as routers. Less expensive as compared to a wired network.

iii. Scalable - accommodate the addition of more nodes.

iv. Robust due to decentralize administration.

v. The network can be set up at any place and time.[10][11]

\section{b. Disadvantages of MANET}

i. Bandwidth constraints: The bandwidth of the wireless links is always much lower than the wired counterparts. Indeed, several Gbps are available for wired LAN, while, nowadays, the commercial applications for wireless LANs work typically around 2 Mbps.

ii. Energy constraints: The power of the batteries is limited in all the devices, which does not allow infinitive operation time for the nodes. Therefore, energy should not be wasted and that is why some energy-conserving algorithms have been implemented.

iii. Transmission Errors: Attenuation and interferences are other effects of the wireless link that increase the error rate.[12][13]

Ad-Hoc can be used in urgent operations for disaster relief efforts, in fire, flood, or earthquake. Saviors must be capable to communicate to make calls for relief and so on. [14]

\section{Setup of Simulation (Methodology)}

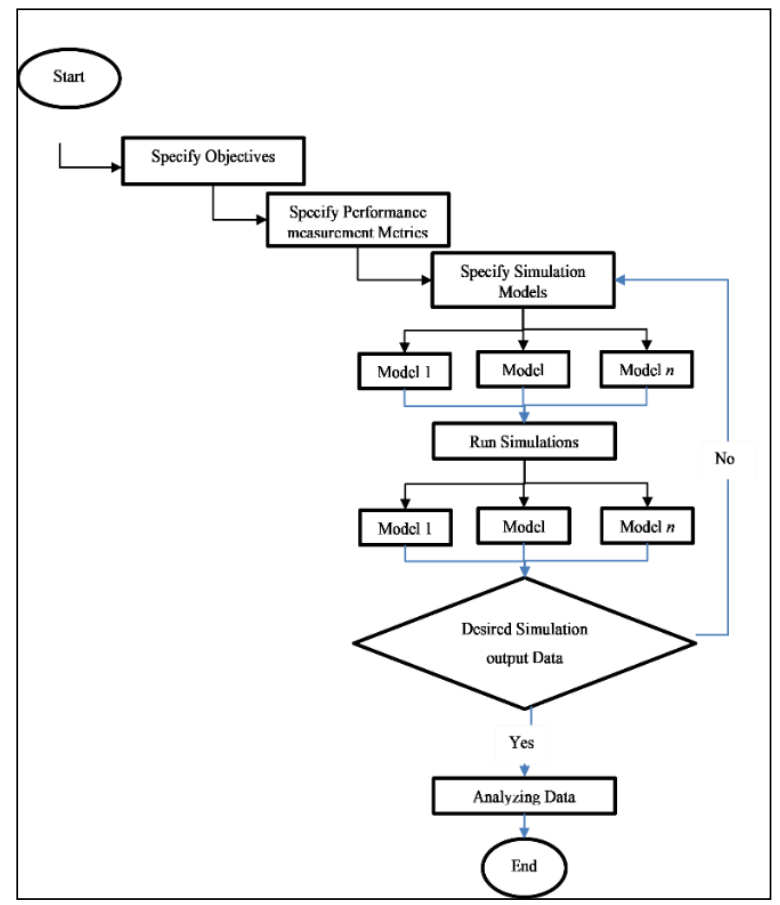

Fig. 1: Steps for a Systematic Simulation Study

A. Objectives of Simulation 
The objective of the simulation is to make a comparative analysis of the performance of the Geographical Routing Protocol in Mobile Ad-Hoc Networks and determine which factor affects the performance of the Geographical Routing Protocol in Mobile Ad-Hoc Networks. Geographical Routing Protocol is a routing principle that relies on the geographic position information. It is mainly proposed for wireless networks and based on the idea that the source sends a message to the geographic location of the destination instead of using the network address. A mobile ad hoc network (MANET), also known as wireless ad hoc network or ad hoc wireless network is a continuously self-configuring, infrastructure-less network of mobile devices connected wirelessly.[8]

\section{B. Performance Metrics}

Packet Loss and End-to-End Delay are the performance metrics that can be taken into account, for getting a general idea about the performance of the Geographical Routing Protocol in Mobile Ad-Hoc Networks. The proposed research will evaluate the parameters which affect the communication in the Geographical Routing Protocol in Mobile Ad-Hoc Networks, using the performance metrics described below.

\section{i. Packet Loss}

Packet delivery ratio is the number of packets received by the destination node successfully, send by the source node. This metric describes the delivery-based abilities of the network higher value of this metric indicates the improved performance of the protocol. This metric characterizes both the correctness and completeness and of the routing protocol consistency of routing protocol by giving its usefulness.[15]

\section{ii. Average End to End Delay}

Average End-to-End Delay is defined as the average time taken by each data packet to reach from source to destination node across the network.[16][17] This may include all the possible delays that are caused by queuing at the interface, buffering during the route discovery, re-transmission based delays, transfer propagation and times, etc. Higher statistics of end-to-end delay represents that the network has congestion and hence the routing protocol is not performing efficiently. This statistic can be calculated using equation 1 .

$$
\text { end to end delay }=\sum \frac{\text { (arrival time-transmission time })}{\text { number of packets delivered }} \quad \text { Equation } 1
$$

\section{Simulation Platform}

Riverbed Modeler Academic Edition 17.5 is used for the simulations. This software has a well-described user interface and a good set of modules through which users can professionally create the appropriate environment for their proposed simulation and can drag the object-related modules. This tool is based on the Discrete Event System (DES) and object-oriented methodologies. In this report, Riverbed Simulation 17.5 is used for designing and developing the proposed simulation model.

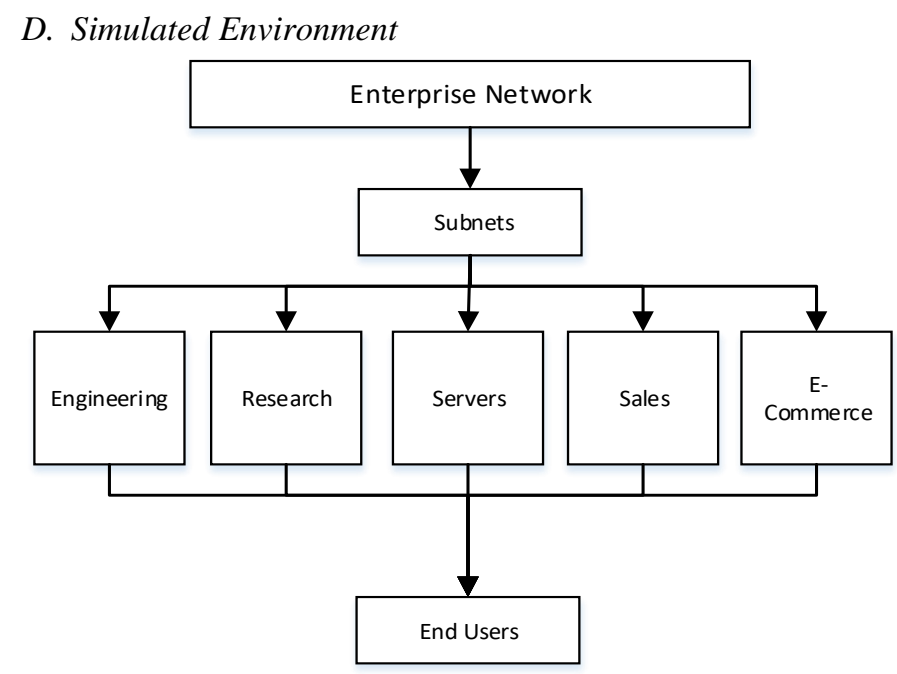

Fig. 2: Simulated Network Structure

The simulated environment is a campus network with four subnets and a server farm as shown in Fig. 3.

\section{i. Application Configuration}

Application configuration specifies applications using available application types. We specified names and the corresponding descriptions in the process of creating new applications. For example, "Web Browsing (Heavy HTTP 1.1)" indicates a web application performing heavy browsing using HTTP 1.1. The specified application name will be used while creating user profiles on the "Profile Config" object. In the application definition, we configured three application rows in each of the scenarios. The main idea is to allow us to generate more traffic to enable good analysis [8].

\section{ii. Profile Configuration}

The "Profile Config" node can be used to create user profiles. These user profiles can then be specified on different nodes in the network to generate application-layer traffic. The application defined in the "Application Config" objects is used by this object to configure profiles. Therefore, one must create applications using the "Application Config" object before using this object. One can specify the traffic patterns followed by the applications as well as the configured profiles on this object.

The six (6) profiles configured for this work are.
i. Engineer
ii. Researcher
iii. E-Commerce Customer
iv. Sales Person 


\section{v. Multimedia User \\ vi. Mobile User}

iii. Servers

The Three (3) Servers considered are named and configured as shown in

Table 1 below. They are configured to generate enough traffic for analysis.

Table 1: Web server, database server, and file server configurations for the simulation

\begin{tabular}{|l|l|l|l|l|l|l|}
\hline \multirow{2}{*}{ Server } & \multicolumn{3}{|l|}{ Application 1 } & \multicolumn{2}{l|}{ Application 3 } & \multicolumn{2}{l|}{ Application 3 } \\
\cline { 2 - 7 } & Type & Load & Type & Load & Type & Load \\
\hline Web & $\begin{array}{l}\text { Web } \\
\text { Browsin } \\
\text { g }\end{array}$ & $\begin{array}{l}\text { Heav } \\
\mathrm{y}\end{array}$ & Email & Light & $\begin{array}{l}\text { Telnet } \\
\text { Sessio } \\
\mathrm{n}\end{array}$ & Light \\
\hline File & $\begin{array}{l}\text { File } \\
\text { Transfer }\end{array}$ & Light & File Print & Light & - & - \\
\hline $\begin{array}{l}\text { Databas } \\
\text { e }\end{array}$ & $\begin{array}{l}\text { Databas } \\
\text { e Access }\end{array}$ & $\begin{array}{l}\text { Heav } \\
\mathrm{y}\end{array}$ & $\begin{array}{l}\text { Video } \\
\text { Streamin } \\
\mathrm{g}\end{array}$ & $\begin{array}{l}\text { Heav } \\
\mathrm{y}\end{array}$ & Email & $\begin{array}{l}\text { Heav } \\
\mathrm{y}\end{array}$ \\
\hline
\end{tabular}

\section{Results and Analysis}

For analysis of results, we considered three topologies which are, Star Topology, Mesh Topology, and Wireless Topology. Each of these three topologies is analyzed for the variable Ethernet delay, FTP traffic sent and received, FTP Upload and download response time, HTTP traffic sent and received, HTTP object, and page response times.

Mesh topologies always give one-to-one connectivity set up which is believed to optimize the functionality of the network. On the same note, star topology is affected by the number of nodes connected in a network. As the number of nodes increases the performance of the network tends to decrease. In this case, the relationship between performance and the network size is inverse. This is because there will be only one central node managing a vast number of nodes. For Adhoc networks, they are mostly configured using WLAN protocols. These allow any time anywhere connectivity of devices to the network provided the network administrators to set the network to work according to the user's demands. This setup is very difficult to monitor and the performance is highly unpredictable. Because of the anytime-anywhere connectivity capabilities, the protocols regulating Adhoc networks include some GRPs for location services. In this work, we, therefore, base all our analysis on a comparison of the three most fashionable network topologies as suggested above.
The first element of analysis in this work was ethernet performance as shown in Fig. 4. The graph shows ethernet delay variations measured in seconds for star topology, wireless topology, and Mesh topology. Maximum Ethernet delay was observed at two minutes for wireless topology and recorded to be $0.0027 \mathrm{~s}$. From the three topologies, the overall wireless topology generates the highest Delay followed by star topology, and mesh topology has the lowest delay. To quantify the comparative results, reading were extracted from all the graphs at 6 minutes of simulation. In the case of ethernet delay,

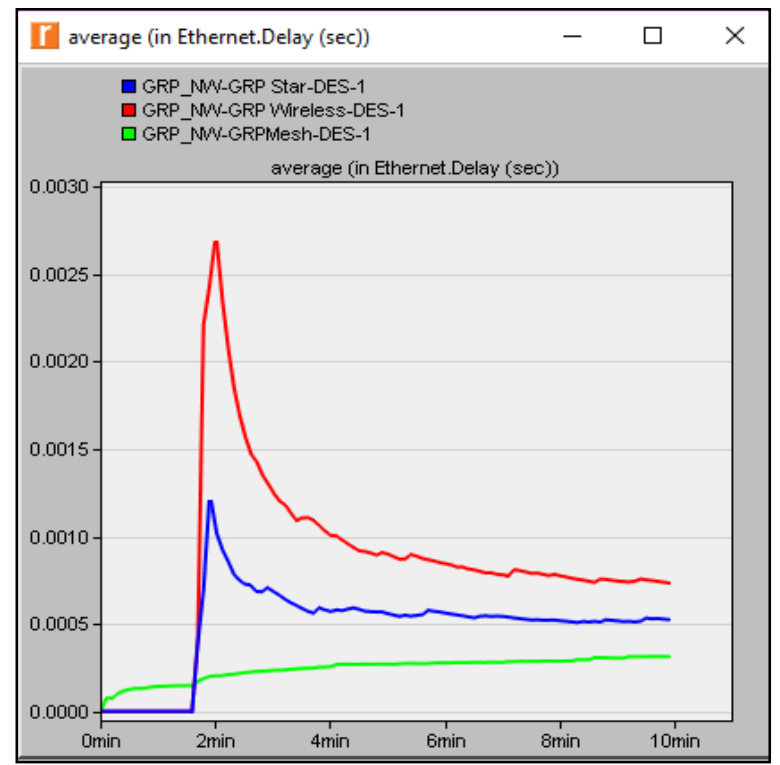

Fig. 5: Ethernet Delay

$\begin{array}{rlr}\text { i. } & \text { Star } & =0.0006 \mathrm{~s} \\ \text { ii. } & \text { Mesh } & =0.0003 \mathrm{~s} \\ \text { iii. } & \text { Wireless } & =0.0008 \mathrm{~s}\end{array}$

To compare the performances the following calculations were done.

$$
\begin{aligned}
& \text { performance between star vs mesh topology } \\
& \qquad=\frac{0.0006-0.0003}{0.0006} \times 100 \%=50 \%, \\
& \text { perfromance between wireless vs mesh }=\frac{0.0008-0.0003}{0.0008} \times 100 \% \\
& =63 \%,
\end{aligned}
$$

The results for all the other metrics and topologies are summarized in Table 2. below. The first entry of results is for the ethernet delay and is calculated as shown above. The other entries are similarly calculated as presented above. Results for the metric are extracted from Fig 3. To Fig 11. At six (6) minutes of simulations.

Table 3: Summary of performance comparison between different performance metrics and topologies.

\begin{tabular}{|l|c|c|c|c|c|}
\hline & \multicolumn{3}{|c|}{ Topology } & \multicolumn{2}{c|}{ Percentage Differences } \\
\hline & Star & Mesh & WLAN & Star vs Mesh & WLAN vs Mesh \\
\hline Ethernet Delay & $0.0006 \mathrm{~s}$ & $0.0003 \mathrm{~s}$ & $0.0008 \mathrm{~s}$ & $50 \%$ & $63 \%$ \\
\hline FTP Traffic Received & $0.03 \mathrm{pkt} / \mathrm{s}$ & $0.01 \mathrm{pkt} / \mathrm{s}$ & $0.06 \mathrm{pkt} / \mathrm{s}$ & $67 \%$ & $83 \%$ \\
\hline FTP Traffic Sent & $0.3 \mathrm{pkt} / \mathrm{s}$ & $0.1 \mathrm{pkt} / \mathrm{s}$ & $0.6 \mathrm{pkt} / \mathrm{s}$ & $67 \%$ & $83 \%$ \\
\hline
\end{tabular}




\begin{tabular}{|l|c|c|c|c|c|}
\hline FTP download response time & $0.14 \mathrm{~s}$ & $0.07 \mathrm{~s}$ & $0.24 \mathrm{~s}$ & $50 \%$ & $70 \%$ \\
\hline FTP upload response time & $0.17 \mathrm{~s}$ & $0.09 \mathrm{~s}$ & $0.20 \mathrm{~s}$ & $47 \%$ & $55 \%$ \\
\hline HTTP traffic received & $20 \mathrm{pkt} / \mathrm{s}$ & $6 \mathrm{pkt} / \mathrm{s}$ & $50 \mathrm{pkt} / \mathrm{s}$ & $70 \%$ & $88 \%$ \\
\hline HTTP traffic sent & $68 \mathrm{pkt} / \mathrm{s}$ & $20 \mathrm{pkt} / \mathrm{s}$ & $175 \mathrm{pkt} / \mathrm{s}$ & $70 \%$ & $88 \%$ \\
\hline HTTP Object response time & $0.14 \mathrm{~s}$ & $0.12 \mathrm{~s}$ & $0.22 \mathrm{~s}$ & $14 \%$ & $45 \%$ \\
\hline HTTP page response time & $0.6 \mathrm{~s}$ & $0.5 \mathrm{~s}$ & $0.9 \mathrm{~s}$ & $17 \%$ & $44 \%$ \\
\hline
\end{tabular}

Taking Mesh topology as the base for comparison we compared the results as percentage variations from mesh to either star or WLAN. As mentioned earlier WLAN is the base topology for Adhoc networks. But before, between, or after every WLAN network is a wired network. The characteristic of the performance of an entire WLAN network is a culmination of the resultant hybrid network. That is why it is necessary to study the wired and wireless scenarios for all the metrics.

An analysis of the summarized results is given in the following section.

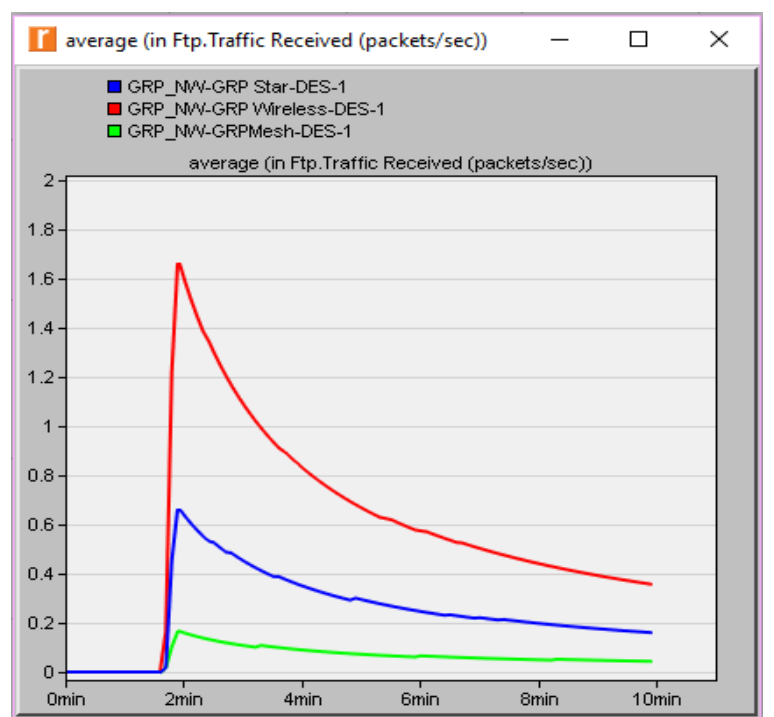

Fig. 6: FTP Traffic Received

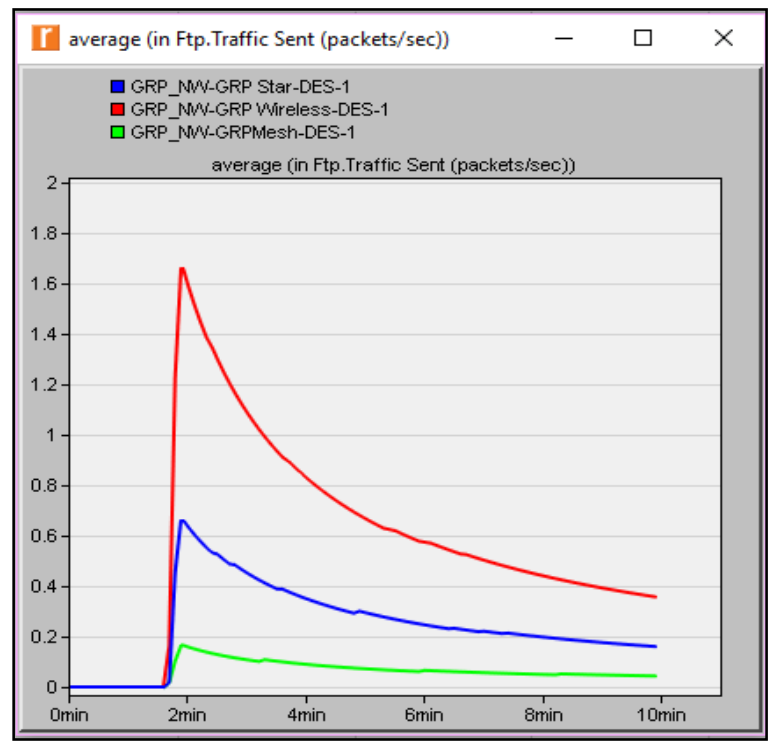

Fig. 7: FTP Traffic Sent

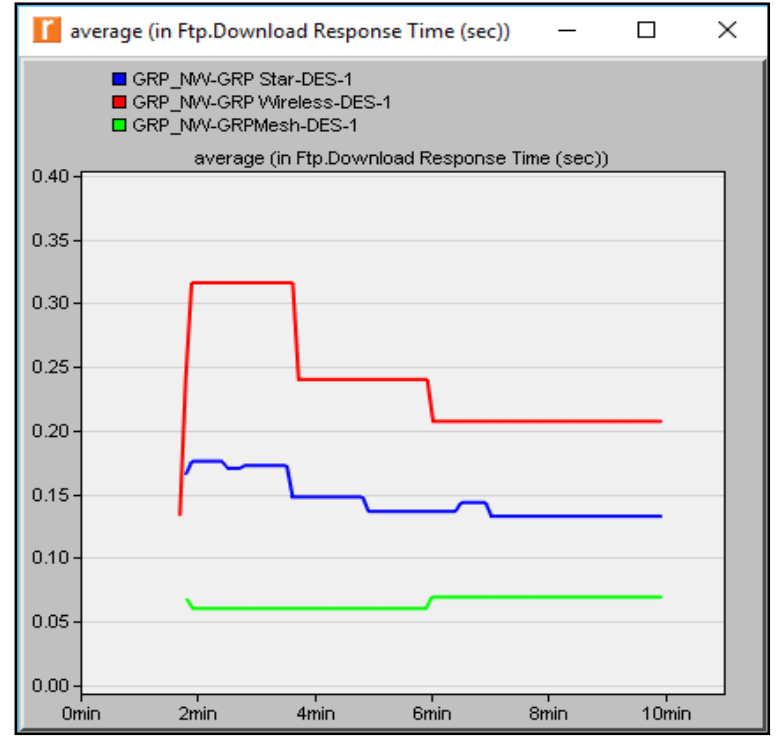

Fig. 8: FTP Download Response Time

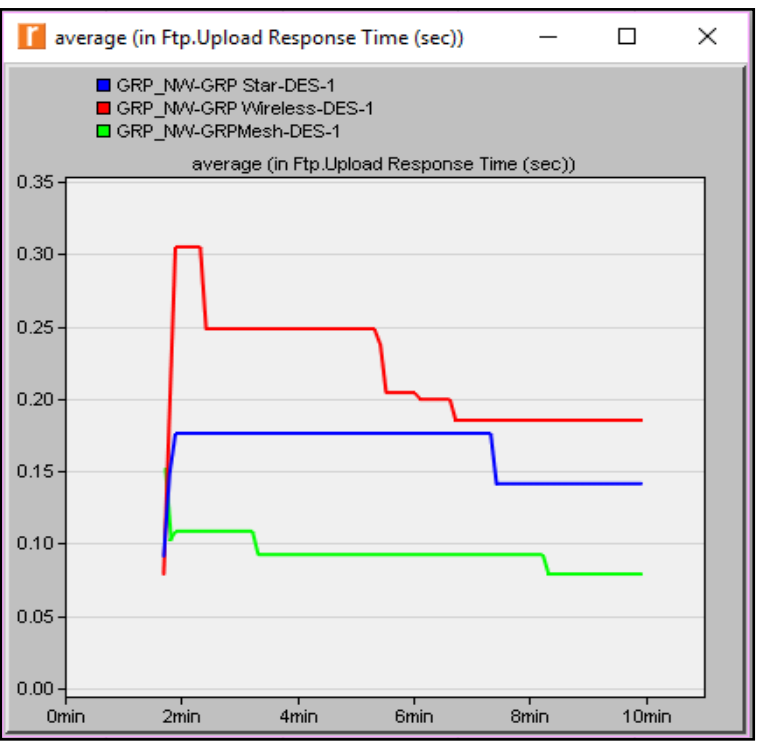

Fig. 9: FTP Upload Response Time 


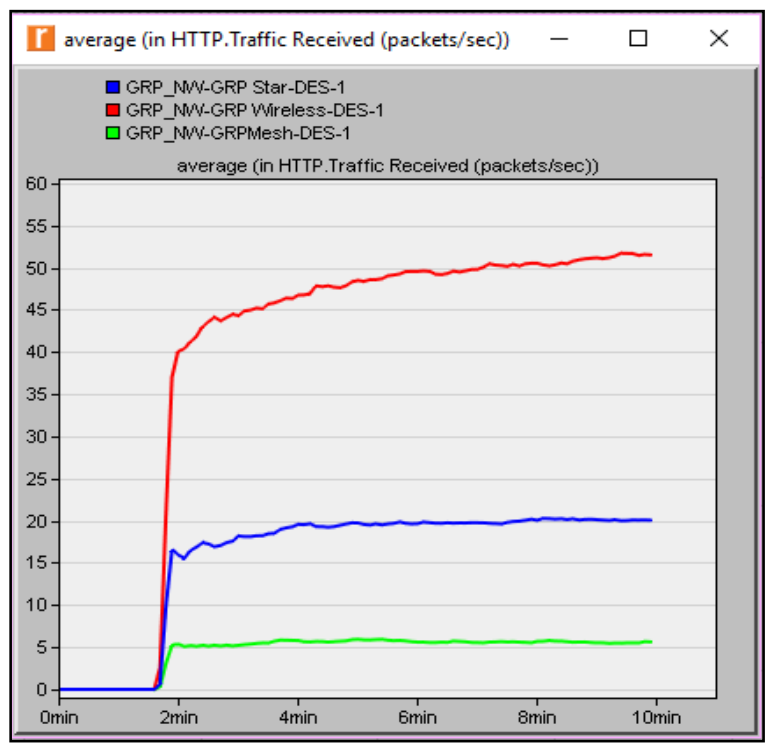

Fig. 10: HTTP Traffic Received

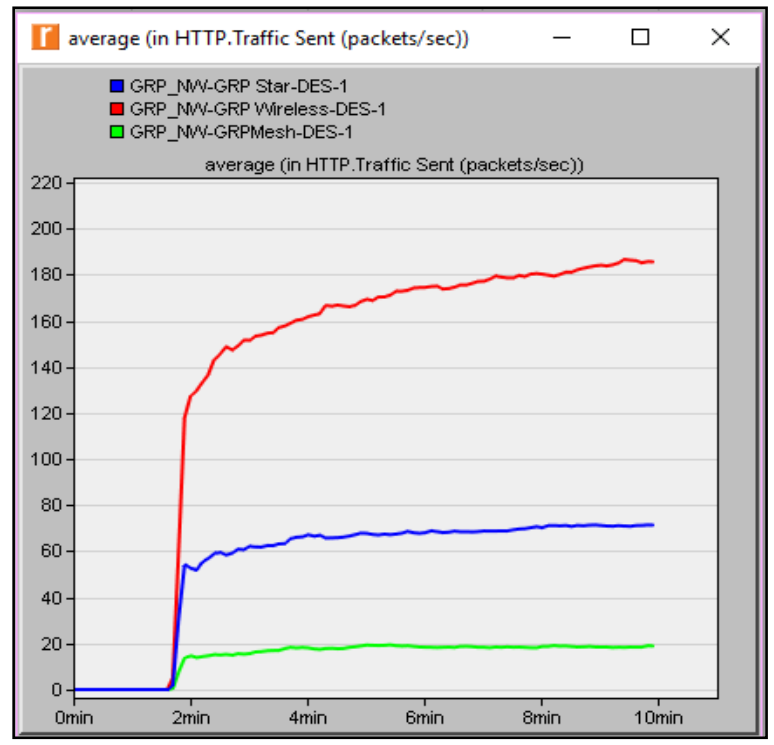

Fig. 11: HTTP Traffic Sent

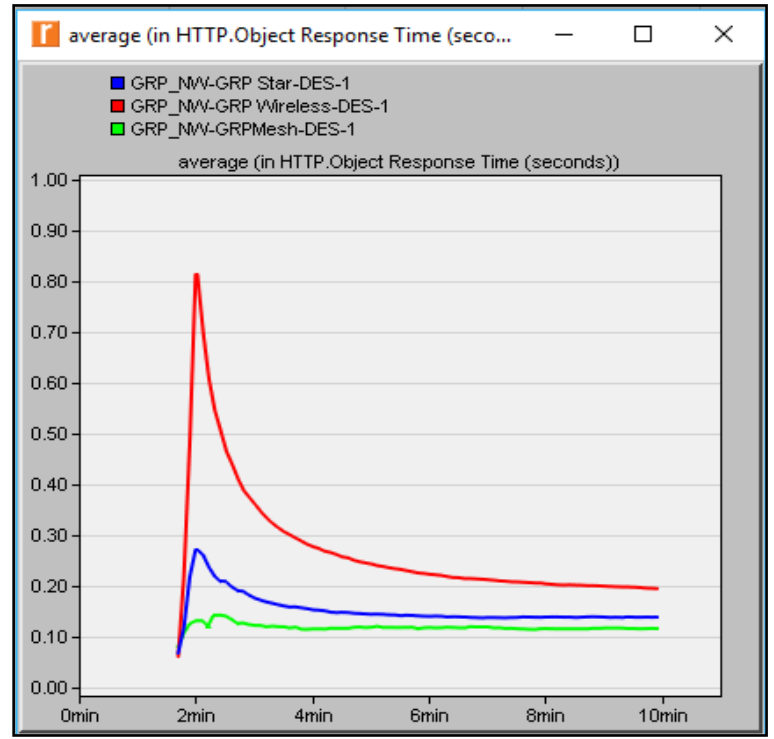

Fig. 12: HTTP Object Response Time (seconds)

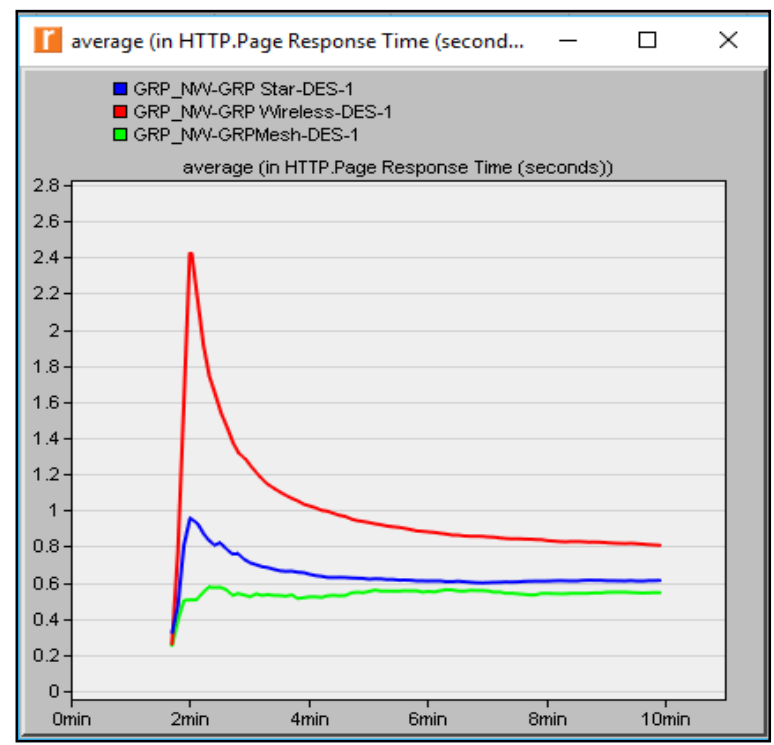

Fig. 13: HTTP Page Response Time (seconds)

The results presented in Table 2. shows that's WLAN does not handle delay well. In this case, MESH topology has the best performance followed by Start topology in terms of delay. This might be because the delay in WLAN topology is a cumulative delay of several topologies as discussed earlier on the nature of WLAN topologies. Considering Traffic received, and traffic sent, WLAN topology performs much better than mesh and star. This confirms that even though GRPs aid in increasing the number and sizes of data in a network, the WLAN standards are better performers in data transfer.

The FTP response times for upload and download are high in WLANs. This is the downside of GRPs as they introduce delays in both upload and download. This concludes that WLANs are more prone to congestion compared to wired counterparts. The main reason is that WLANs have much better data transfer speeds and capacities compared to wired networks while the processing resources are the same. This is confirmed by the statistic from traffic sent and received. WLAN having up to $175 \mathrm{pkts} / \mathrm{s}$ compared to 20 and 68 for mesh and star respectively. On the downside, the object and page response times for WLAN are very high compared to mesh and star.

\section{Conclusion}

In this project, we have studied and attained results through the use of RIVERBED MODELER a topology simulation tool. By using this simulation tool, we develop proprietary wireless protocols and topologies, evaluate the servers using different applications, and finally test and demonstrate performance differences brought about by variations in design in realistic scenarios. We have to design an enterprise network and analyze the network from different perspectives. 
The gathered results demonstrated beyond doubt that an Adhoc network is a better performer in terms of data transfer. The result however falls short in the processing of such high amounts of data resulting in delays culminating in deadlocks and data loss. The design of Adhoc networks therefore should take into consideration the ability of the end nodes and intermediary nodes in processing the information. Networks are not about data transfer only but also data processing. Further studies have to be done to determine how the proposed 5G Gigabit networks will be incorporated into the existing slower networks with slower processing devices in such a manner that system performances are not compromised.

\section{Acknowledgment}

The authors would like to thank the Faculty of Creative Media and Innovative Technology (FCMIT) and the Department of Networking in IUKL for the support and provision of resources and working environment.

\section{References}

[1] S. G. Fantar and H. Youssef, "Locality-aware Chord over Mobile Ad Hoc Networks," Glob. Inf. Infrastruct. Symp., pp. 1-6, 2009.

[2] S. Rahul, "Performance Analysis of AODV, DYMO and Bellman Routing Protocols in Mobile Ad-Hoc Network," J. Theor. Appl. Inf. Technol., vol. 2013, no. Cac2s, pp. 346-349, 2013.

[3] T. E. Nyamasvisva and H. Hasbullah, "Multi-level security algorithm for random ZigBee Wireless Sensor Networks," Inf. Technol. (ITSim), 2010 Int. Symp., vol. 2, pp. 612-617, 2010.

[4] Y.-J. Kim, R. Govindan, B. Karp, and S. Shenker, "On the Pitfalls of Geographic Face Routing," Proc. 2005 Jt. Work. Found. Mob. Comput. (DIALMPOMC '05), pp. 34-43, 2005.

[5] R. S. Battula and S. Dutt, "A Review of LocationBased Geographic Routing Protocols for Wireless Sensor Networks," Int. J. Eng. Res. Technol., vol. 2, no. 6, pp. 1170-1174, 2013

[6] K. Seada, M. Zuniga, A. Helmy, and B. Krishnamachari, "Energy-efficient forwarding strategies for geographic routing in lossy wireless sensor networks," Proc. 2nd Int. Conf. Embed. networked Sens. Syst. - SenSys '04, p. 108, 2004

[7] K. Seada, K. Seada, A. Helmy, and A. Helmy, "Geographic Protocols in Sensor Networks," Electr. Eng., pp. 1-37.

[8] R. Mahajan, "Application and Research on Performance Analysis and Security Implementation in Hybrid Networks," Int. J. Sci. Technol., vol. 4, no. 4, pp. 93-102, 2016.

[9] H. Wang, Y. Wang, and J. Han, "A Security Architecture for Tactical Mobile Ad Hoc Networks," in 2009 Second International Workshop on Knowledge Discovery and Data Mining, 2009, pp. 312-315.
[10] R. Sobti, "A Study on Challenges and Issues on MANET," Int. J. Adv. Res. Electr. Electron. Instrum. Eng., vol. 4, no. 9, pp. 3-6, 2015.

[11] T. S. S. Aarti, "Study of MANET : Characteristics, Challenges, Application and Security Attacks," Int. J. Adv. Res. Comput. Sci. Softw. Eng., vol. 3, no. 5, pp. 252-257, 2013.

[12] P. Kaur, "An Overview on MANET-Advantages, Characteristics and Security Attacks," Int. J. Comput. Appl., no. Icaet, pp. 975-8887, 2016.

[13] S. A. K. Al-Omari and P. Sumari, "An Overview of Mobile Ad Hoc Networks for the Existing Protocols and Applications," Int. J. Appl. graph theory Wirel. ad hoc networks Sens. networks, vol. 2, no. 1, p. 24 2010.

[14] K. Sharma and N. Dhir, "A Study of Wireless Networks: WLANs, WPANs, WMANs, and WWANs with Comparison," IJCSIT Int. J. Comput. Sci. Inf. Technol., vol. 5, no. 6, pp. 7810-7813, 2014.

[15] A. Sheth, S. Nedevschi, R. Patra, S. Surana, E. Brewer, and L. Subramanian, "Packet loss characterization in wifi-based long-distance networks," Proc. - IEEE INFOCOM, pp. 312-320, 2007.

[16] Y. Xie, Z. Li, and M. Li, "Precise Power Delay Profiling with Commodity WiFi," Proc. 21st Annu. Int. Conf. Mob. Comput. Netw. - MobiCom '15, pp. 53-64, 2015.

[17] T. Saleem, "Performance Issues of Routing Protocols in Mobile Ad-hoc Networks," no. September 2010. 